Uluslararası Mühendislik

\title{
Düssey Mantolu Sıcak Su Tanklarının Isıl Performanslarının Enerji Yükleme ve Boşaltma Periyotlarında Deneysel Olarak İncelenmesi
}

\section{Experimental Investigation of Thermal Performance of Vertical Mantled Hot Water Tanks in Energy Charging and Discharging Periods}

\author{
Doğan Erdemir ${ }^{1}$ iD \\ ${ }^{I}$ Erciyes Üniversitesi, Mühendislik Fakültesi, Makine Mühendisliği Bölümü, 38039, Kayseri, Türkiye
}

Başvuru/Received: 04/06/2018

Kabul / Accepted: 05/09/2019

Çevrimiçi Basım / Published Online: 27/09/2019

Son Versiyon/Final Version: 31/01/2020

\begin{abstract}
$\ddot{O} \mathbf{z}$
Sıcak su tankları 1sıl enerji depolamanın yaygın kullanılan metotlarından biridir. Bu çalışmada; güneş enerjili sıcak su ve diğer muhtelif sıcak su elde etme sistemlerinde yaygın bir şekilde kullanılan düşey mantolu sıcak su tanklarının isıl performansları deneysel olarak incelenmiştir. Çalışmada 450 litrelik bir düşey mantolu sıcak su tankı için enerji yükleme ve boşaltma periyotlarındaki sıcaklık tabakalaşması farklı çalışma koşullarında araştırılmıştır. Manto giriş sıcaklığ 150,60 ve $70{ }^{\circ} \mathrm{C}$, manto debisi $2.5,5$ ve $7.5 \mathrm{l} / \mathrm{dk}$ ve şebeke debisi 5,10 ve 15 l/dk olarak alınmıştır. Deneyler sırasında şebeke giriş sıcaklığ ve ortam sıcaklığı sabit kalmıştır. Deneylerde ilk olarak 3 saatlik süre boyunca enerji yükleme periyodu gerçekleştirilmiştir. Ardından ise kullanım suyu çıkış sıcaklığı $30^{\circ} \mathrm{C}$ 'ye düşene kadar enerji boşaltma periyodu gerçekleştirilmiştir. Çalışmanın sonucunda; fark lı işletme şartlarında tank içerisindeki sıcaklıkların zamanla değişim davranışı yaklaşık olarak aynı olduğu görülmüştür. Ayrıca, tanktan edilen sıcak miktarı üzerinde, şebeke giriş debisinin önemli bir etkiye sahip olduğu ve artan her 5 l/dk debinin elde edilen sıcak su miktarını yaklaşık 20 litre düşürdüğ̈̈ gözlemlenmiştir.
\end{abstract}

\section{Anahtar Kelimeler}

"Düşey mantolu sicak su tankl, Sicak su tankl, Güneş enerjili sıcak su sistemi, Isll enerji depolama"

\begin{abstract}
Hot water tanks are one of the common methods of thermal energy storage. In this study, the thermal performance of vertical hot water tanks which are widely used in solar domestic hot water systems and various other hot water obtaining systems are investigated experimentally. In this study, the temperature stratification for a 450-liter vertical mantled hot water tank was investigated under different operating conditions during the energy charging and discharging periods. Mantle inlet temperature was 50, 60 and $70{ }^{\circ} \mathrm{C}$, mantle flow rate was 2.5, 5 and $7.51 / \mathrm{min}$ and main line flow rate is 5, 10 and $151 / \mathrm{min}$. Main line inlet and ambient temperatures remained constant. During the experiments, the energy charging period was carried out for 3 hours. Then the energy ing period was carried out until the domestic water outlet temperature decreased to $30^{\circ} \mathrm{C}$. As a result of the study; it was found that the temperature distribution changing behavior was approximately the same in different operating conditions. Furthermore, it was seen that main line inlet flow rate has a significant effect on the amount of hot water from the tank. When main line flow rate increased 51/min, the amount of hot water obtained from the tank decreased nearly 20 liters.
\end{abstract}

Key Words

"Vertical hot water tank, Hot water tank, Solar domestic hot water system, Thermal energy storage" 


\section{Giriş}

Enerji depolama; enerji kaynağının aktif olmadığı dönemlerde de kullanılmasına devam etmek, enerji tüketim maliyetlerini düşürmek ya da enerji pik yüklerini pik olmayan zamanlara kaydırmak için kullanılabilecek en önemli araçlardan biridir. Bu yüzden, enerji dönüşüm sistemlerinde yaygın olarak kullanmaktadır. Ayrıca, yenilebilir enerji kaynakları doğası gereği sürekli olarak aktif olmadıklarından, bu kaynaklardan enerji kaynağı aktif değilken de yararlanmak için enerji depolama yöntemleri kullanılmaktadır. Enerji; her bir enerji türünde depolanmaktadır. Enerji depolama yöntemlerinin avantajları (Dincer and Rosen 2011) tarafından sıralanmıştır. Ayrıca (Acar 2018) teknik olgunluk, çevresel etki, maliyet, ömür gibi kriterler üzerinden enerji depolama sistemlerini karşılaştırmıştır. Isıl enerji depolama, enerji depolama yöntemleri arasında en eski ve olgunlaşmış türlerden biridir. Ayrıca üretilen ve tüketilen enerjinin büyük kısmı da 1sı olduğundan 1sıl enerji depolama sistemleri zaman içerisinde çok sayıda araştırmacı tarafından incelenmiştir. Güneş enerjili sıcak su sistemleri hem yenilebilir enerji uygulaması hem de enerji depolama uygulaması olarak yaygın kullanılan sistemlerden biridir. Sicak su depolama tankları, 1sıl enerji depolamanın en temel uygulamalarından biridir. Bu sebepten sıcak su tanklarının tasarımı, 1sıl performanslarının belirleme yöntemleri ve 1sıl performanslarını iyileştirme ile alakalı çok sayıda çalışma bulunmaktadır. Sıcak su tanklarındaki en önemli performans kriteri tank içerisindeki sıcaklık tabakalaşmasıdır. İyileştirilmiş sıcaklık tabakalaşması sıcak su tanklarının ısıl enerji depolama performansını arttırmaktadır.

(Kurşun and Ökten 2018) prizmatik bir sıcak su tankında tankın konumlandırma açısının ve en/boy oranının sıcaklık tabakalaşması üzerindeki etkilerini sayısal olarak araştırmıştır. Çalışmanın sonucunda en iyi sıcaklık tabakalaşmasının tankın yatayla $45^{\circ}$ açı yaptığı ve D/H oranının 0.5 olduğu durumda görülmüştür. (Kurşun 2018) silindirik ve prizmatik sıcak su tanklarında, tank tabanından üst kısımlarına doğru farklı kalınlıklarda yalıtım uygulaması yapılmasının sıcaklık tabakalaşması üzerindeki etkisini sayısal olarak incelemişlerdir. Bu çalışmanın sonucunda, prizmatik ya da kesik koni şeklindeki yalıtım uygulamalarının sıcaklık tabakalaşmasını iyileştirdiği tespit edilmiştir. (Arslan and Igci 2015) mantolu 1sı değiştiricisine sahip bir sıcak su tankındaki sıcaklık tabakalaşmasını enerji boşaltma dönemi için sayısal olarak incelemişlerdir. (Erdemir and Altuntop 2016) mantolu sicak su tanklarındaki sıcaklık tabakalaşmasının tank içerisine yerleştirilen engeller ile iyileştirilmesini manto ve şebeke çevriminin aktif olduğu durumlarda deneysel olarak araştırmışlardır. Ayrıca yine (Erdemir and Altuntop 2016) sıcaklık tabakalaşmasının düşey mantolu sıcak su tankının enerji ve ekserji verimliliği üzerindeki etkisini incelemişlerdir. (Chandra and Matuska 2019) sıcak su tanklarının tasarım kriterlerinin ve işletme şartlarının sıcaklık tabakalaşması üzerindeki etkilerini irdeleyen kapsamlı bir derleme ve değerlendirme çalışması gerçekleştirmiştir. (Deng, Furbo et al. 2018) mantolu sıcak su tanklarında manto içerisinde faz değiştiren malzeme kullanımının sıcaklık tabakalaşması üzerindeki etkisini incelemişlerdir. (Kurşun and Ökten 2016) düşey sıcak su tanklarında farklı D/H oranlarında yalıtım kalınlığının sıcaklık tabakalaşması üzerindeki etkisi araştırmışlardır. (Dragsted, Furbo et al. 2017) sıcak su tanklarında farklı giriş tabakalaştırıcılarının sıcaklık tabakalaşması üzerindeki etkisini incelemişlerdir. (Bouhal, Fertahi et al. 2017) sıcaklık tabakalaşmasının farklı çalışma koşullarında optimize etmeye yönelik bir çalışma gerçekleştirmişlerdir. (Fan, Furbo et al. 2015) sıcak su tanklarındaki sıcaklık tabakalaşmasını daha iyi tahminlemek için bir simülasyon programı geliştirmişlerdir. (Fan and Furbo 2012) sıcak su tanklarında bekleme periyodunda gerçekleşen ısı kaybının sıcaklık tabakalaşması üzerindeki etkisini incelemişlerdir. (Kenjo, Inard et al. 2007) düşey mantolu sıcak su tanklarında sıcaklık tabakalaşmasını deneysel ve sayısal olarak incelemişlerdir. (Assari, Basirat Tabrizi et al. 2018) tank giriş ve çıkışlarının tankın ısıl enerji depolama performansı üzerindeki etkisini incelemişlerdir. (Dehghan and Barzegar 2011) enerji boşaltma periyodunda tankın sıcaklık tabakalaşmasının nasıl etkilendiğini belirlemek için sayısal bir çalışma gerçekleştirmişlerdir. (Zachár 2015) serpantinli bir sıcak su tankında yeni helisel bir dağıtıcı kullanımının enerji boşaltma döneminde sıcaklık tabakalaşması üzerindeki etkisini araştırmışlardır. (Fertahi, Jamil et al. 2018) sıcaklık tabakalaşmasını iyileştiren ve sıcaklık tabakalaşmasının derecesini belirleyen parametreleri inceleyen bir derleme ve değerlendirme çalışması yapmışlardır.

Güneş enerjili sıcak 1sıtma sistemleri hem yenilenebilir enerji uygulaması hem de 1sıl enerji uygulaması olarak yaygın bir şekilde kullanılmaktadır. Bu yüzden, sıcak su depolarının performanslarının iyileştirilmesi bir mühendislik uygulaması olarak önemli bir konudur. Bu çalışmanın temel amacı, düşey mantolu sıcak su tanklarındaki sıcaklık tabakalaşmasının farklı çalışma koşulları altında nasıl etkilendiğini deneysel olarak belirlemektedir. Bu kapsamda, güneş enerjili ve diğer sıcak su elde sistemlerinde yaygın olarak kullanılan düşey mantolu sıcaklık tankındaki sıcaklık tabakalaşması enerji boşaltma ve yükleme periyotlarında incelenmiştir. Ayrıca farklı çalışma koşullarında tanktan ne kadar sıcak su temin edilebileceği deneysel olarak araştırılmıştır.

\begin{tabular}{|c|c|}
\hline \multicolumn{2}{|c|}{ Terminol } \\
\hline$T_{m, g}$ & Manto giriş sıcaklı̆̆l \\
\hline$T_{m, c}$ & Manto çıklş sıcaklı̆̆l \\
\hline$T_{s, g}$ & Şebeke giriş sicakliğl \\
\hline$T_{S, \mathcal{C}}$ & Şebeke çıkış sıcaklığ \\
\hline$V_{\text {manto }}$ & Manto debisi \\
\hline$V_{\text {şebeke }}$ & Şebeke debisi \\
\hline$S$ & Sensör \\
\hline
\end{tabular}




\section{Materyal ve Metot}

\subsection{Deney Sistemi}

Bu çalışmada Şekil 1'de görülen deney sistemi kullanılmıştır. Şekil 1'den görüldüğü üzere, deney sistemi; test tankı, 1sıtıcı, varyak trafo, pompa, bilgisayar, veri toplayıcı ve genleşme tankından oluşmaktadır. Ayrıca manto ve şebeke çevrimindeki akışkan debisini ölçmek için 2 adet debimetre kullanılmıştır. Tankın içerisindeki, giriş ve çıkışlarındaki sıcaklıklar PT100 tipi termokupllar ile ölçülmüştür. Manto ve şebekeden geçen akışkanların debisini kontrol etmek için vanalar kullanılmıștır. Issıtıcı tank (II) içerisinde toplamda $15 \mathrm{~kW}$ güce sahip rezistans bulunmaktadır ve rezistanslara varyak trafo (III) vasıtası ile farklı akımda güç sağlanarak test tankı için sıcak su üretilmektedir. Isıtıcı içerisindeki üretilen suyun sıcaklığını $\pm 2{ }^{\circ} \mathrm{C}$ sicaklıkta sabit tutmak için varyak trafonun üzerindeki bir otomatik kontrol birimi bulunmaktadır. Isıtıcı tanktaki su, bir sirkülasyon pompası (IV) aracılığıyla test tankının manto kısmına pompalanmaktadır. Şebeke çevrimi ise direk olarak ana şebekeden alınan su ile sağlanmaktadır. Bu yüzden deneylerde şebeke suyu giriş sıcaklığı yaklaşık olarak sabit kalmıştır. Deney sistemindeki sıcaklık farklılıklarından kaynaklanan hacim değişimlerinin sisteme zarar vermemesi için bir genleşme tankı (VII) entegre edilmiştir. Termokupllardan ve debimetrelerden gelen bilgileri toplamak ve işlemek için bir adet ELIMKO E680 marka ve model veri toplayıcı (VI) kullanılmıştır. Veri toplayıcı sistemi ile her 10s bir ölçüm değerleri alınmıștır. Alınan verilerin ișlenmesi ve kaydedilmesi için bir adet bilgisayar (V) kullanılmıştır. Debi ölçümlerinde KOBOLT DPM marka debimetreler kullanılmıştır. Debi ölçümleri $\pm \% 1.5$ ve sıcaklık ölçümleri ise $\pm 0.5^{\circ} \mathrm{C}$ hassasiyet ile gerçekleştirilmiştir.

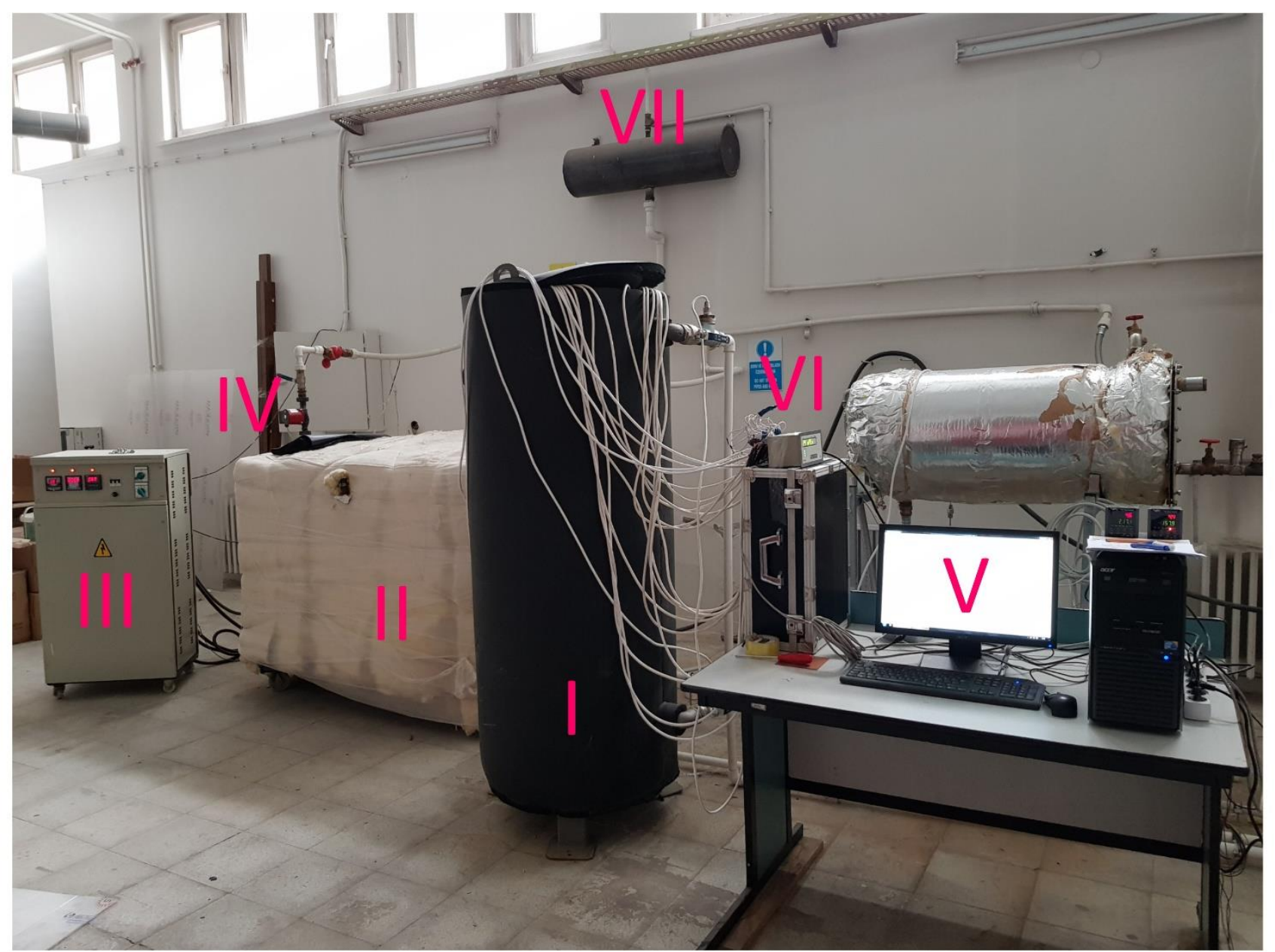

Şekil. 1. Deney sisteminin görünümü (I: test tankı, II: 1sıtıc1, III: varyak trafo, IV: pompa, V: bilgisayar, VI: veri toplayıcı, VII: genleşme tank1)

\subsection{Test Tankı}

Bu çalışmada Şekil 1'de görülen ve Şekil 2'de şematik verilmiş olan 450 litre depolama hacmine sahip düşey mantolu sıcak su tankı kullanılmıştır. Tankın ölçüleri Şekil 2.b'de verilmiştir. Tank $1.5 \mathrm{~mm}$ kalınlığında paslanmaz çelik levhadan üretilmiştir. Tankın giriş ve çıkışları 50 mm çaptadır. Tanktan çevreye olan 1sı kaybını azaltmak için tankın üzeri 6 cm kalınlığında kauçuk köpük yalıtım malzemesi ile kaplanmıştır. Tankın içerisine tank tabanından her $10 \mathrm{~cm}$ 'de bir sıcaklık ölçümü almak için 16 adet termokupl yerleştirilmiştir. Termokuplların tank içerisinde sabit konum tutmak için $40 \mathrm{~mm}$ genişliğinde bir çubuk kullanılmıştır. Şekil 2.a'dan görüldüğü üzere, termokupllar tankın alt tarafından üst tarafına doğru S1, S2 ... S16 olarak sırasıyla adlandırılmıştır. 


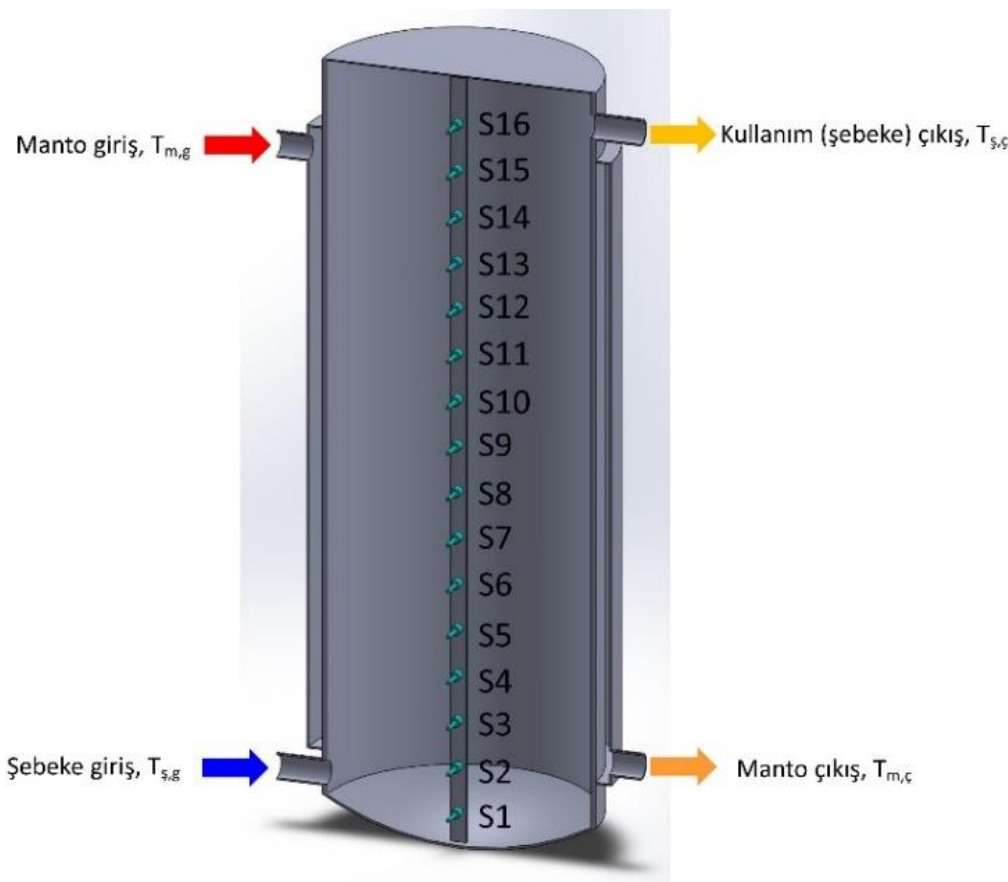

(a)

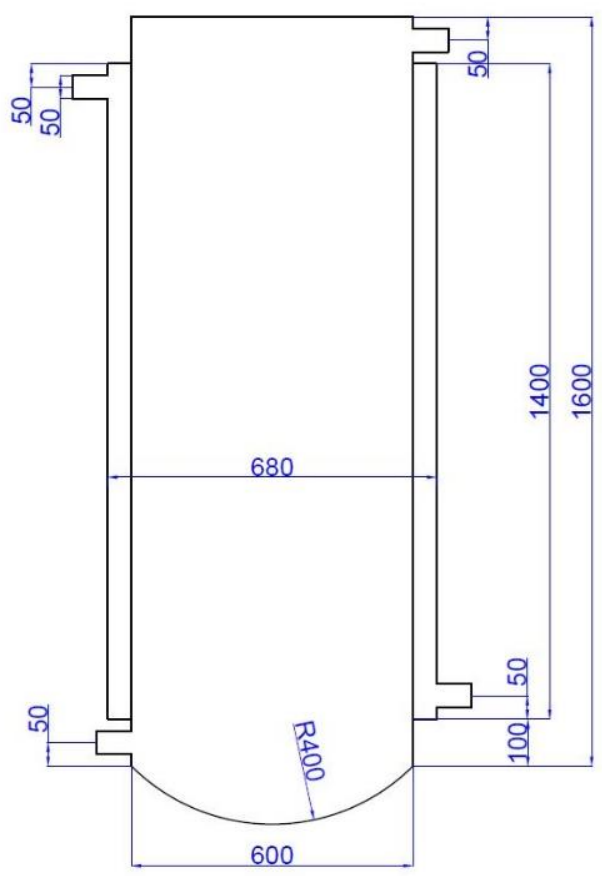

(b)

Şekil. 2. Çalışmada kullanılan düşey mantolu sıcak su tankının (a) Şematik gösterimi; (b) Ölçüleri

\subsection{Deney Prosedürü}

$\mathrm{Bu}$ çalı̧̧ma kapsamında, üç farklı manto giriş sıcaklığının $\left(50,60\right.$ ve $\left.70^{\circ} \mathrm{C}\right)$, üç farklı manto giriş debisinin $(2.5,5,7.5 \mathrm{l} / \mathrm{dk})$ ve üç farklı şebeke giriş debisinin $(5,10$ ve $15 \mathrm{l} / \mathrm{dk})$ sıcaklık tabakalaşması üzerindeki etkisi araşsırılmıştır. Çalışma kapsamında şebekeden gelen su direk olarak kullanıldığ 1 için şebeke suyu sıcaklığ 1 çalışma boyunca yaklaşık olarak $18{ }^{\circ} \mathrm{C}^{\prime}$ de kalmıştır. Deneyler sırasında ilk olarak enerji yükleme deneyi gerçekleştirilmiştir. Enerji yükleme deneyinde manto çevrimi aktif hale getirilmiş 1sıtıcıda (II) belli sıcaklıkta tutulan sıcak su pompa (IV) aracılığı ile test tankına (I) yollanmıştır. Böylece test tankı (I) içerisindeki su 1sıtılmıştır. Enerji yükleme periyodu 3 saatlik bir süre için gerçekleştirilmiştir. Enerji yükleme deneyinin tamamlanmasının hemen ardından enerji boşaltma deneyi yapılmıştır. Enerji yükleme periyodunda tank içerisindeki depolanan sıcak su, şebekeden gelen suyun tanka gönderilmesi ile tanktan alınmıştır. Enerji boşaltma periyodunda manto çevrimi kapalı durumdadır. Deneysel sırasında tank içerisinden 16 sıcaklık, tankın giriş ve çıkışlarındaki 4 sıcaklık ve 1 ortam sıcaklığı olmak üzere 21 sıcaklık değeri her 10 s'de bir ölçülmüştür. Manto ve şebeke hatlarındaki suyun debisi ise anlık olarak yine her 10 s'de ölçülerek kaydedilmiştir. Ayrıca deneyler sırasında manto çevriminde dolaşan toplam su hacmi ve tanktan alınan toplam sıcak su miktarı da ölçülmüştür.

\section{Bulgular ve Tartışma}

\subsection{Enerji Yükleme Periyodu için Sonuçlar}

Düşey mantolu sıcak su tanklarının kullanıldığı sıcak su hazırlama sistemlerinde enerji yükleme periyodunda sadece manto çevrimi çalışır ve iç tank içerisindeki suyun sıcaklığı arttırılır. Şekil 3'de manto giriş sıcaklığının $\mathrm{T}_{\mathrm{m}, \mathrm{g}}=70^{\circ} \mathrm{C}$ olduğu durumda farklı manto debileri için sıcaklık dağılımının zamanla değişimini göstermektedir. Deneylerin başlangıcında tank içerisinde tüm yüksekliklerde yaklaşık şebeke giriş suyu sıcaklığında bulunmaktadır. Yani tank içerisinde sıcaklık tabakalaşması yoktur. Enerji yükleme periyodunun başlamasıyla beraber tank içerisindeki sıcaklık tabakalaşması oluşmaya başlamış̧ır. 180 dakikalık test süresi sonunda, Şekil 3'de tüm durumlar için tankın tabanından $200 \mathrm{~mm}$ mesafede bir soğuk su bölgesi bulunduğu görülmektedir. Manto debisinin $\dot{V}_{m}=2.5 \mathrm{l} / \mathrm{dk}$ olduğu durumda (Şekil 3.a) tank tabanından $300 \mathrm{~mm}$ sonra sıcaklık artmaya başlamış, takın yarısından $(800 \mathrm{~mm})$ sonra hemen hemen $60^{\circ} \mathrm{C}$ sıcaklıkta bir sıcak su bölgesi vardır. Artan manto giriş debisiyle (Şekil 3.b ve Şekil 3.c) tank tabanından $200 \mathrm{~mm}$ ve $800 \mathrm{~mm}$ arasında olan sicaklık tabakalaşmasının etkisi azalmıştır. $400 \mathrm{~mm}$ mesafeden sonra tank içerisinde sıcak su bölgesi oluşmuştur. Sıcak su bölgeleri $\dot{V}_{m}=5 l / d k$ için yaklaşık olarak $63{ }^{\circ} \mathrm{C}$ iken, $\dot{V}_{m}=7.5 l / d k$ için ise $65{ }^{\circ} \mathrm{C}$ 'dir. $\mathrm{Bu}$ sonuçlardan görüldüğü üzere, artan manto debisi ile tank içerisindeki sıcaklık seviyesi artmıştır. Bu duruma artan manto debisi ile manto ve iç tank arasındaki ısı geçiş katsayısının artması neden olmuştur. Bu çalışma kapsamında irdelenen tüm durumlarda, enerji yükleme periyodundaki sıcaklık dağılım davranışı Şekil 3'deki durumla benzerlik göstermiştir. 


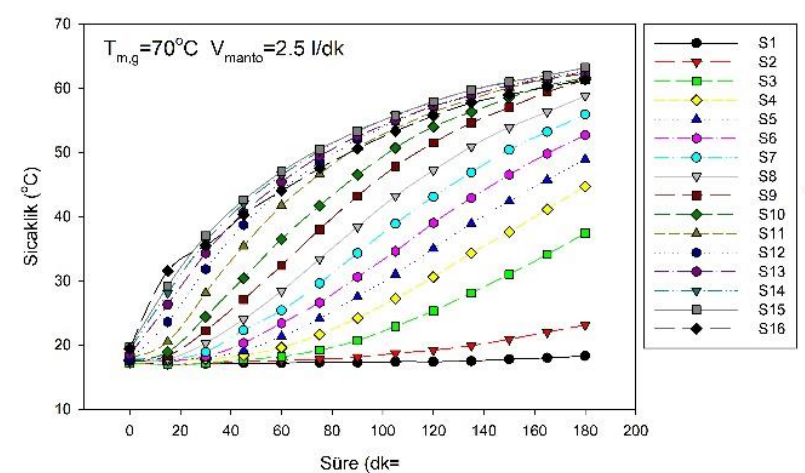

(a)

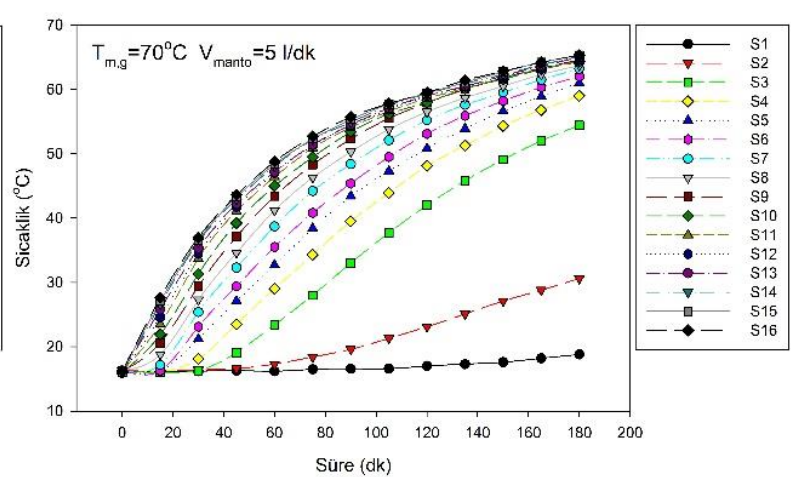

(b)

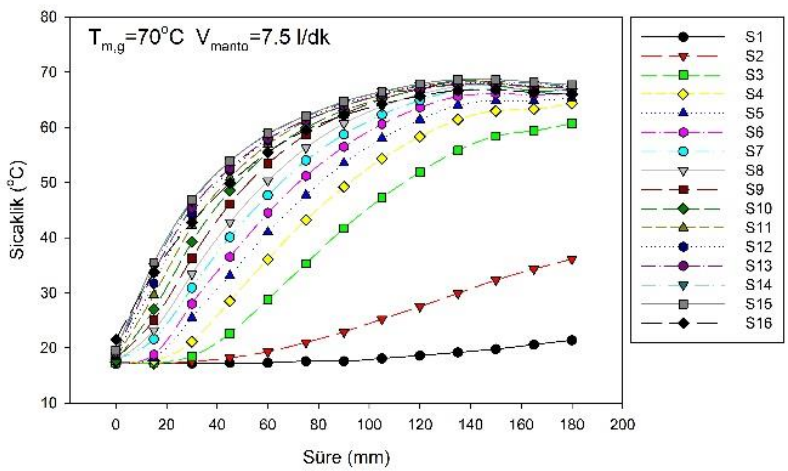

(c)

Şekil. 3. $T_{m, g}=70^{\circ} \mathrm{C}$ olduğu durumda farklı manto giriş hızları için tank içerisindeki sıcaklık dağılımının zamanla değişimi (a)

$$
\dot{V}_{m}=2.5 \mathrm{l} / \mathrm{dk} ; \text { (b) } \dot{V}_{m}=5 \mathrm{l} / \mathrm{dk} ; \text { (c) } \dot{V}_{m}=7.5 \mathrm{l} / \mathrm{dk}
$$

Enerji yükleme periyodunda manto giriş/çıkış ve ortam sıcaklığının zamanla değişimi Şekil 4'te görülmektedir. Şekil 4'ten manto debisinin tanka yüklenen enerji üzerindeki etkisi açık bir şekilde görülmektedir. Artan manto debisi ile manto ile iç tank arasındaki yüzeydeki ısı geçiş miktarı artar. Çünkü artan debi manto içerisindeki akışın Reynold sayısı değerini arttırmaktadır. Artan Reynold sayısı ile türbülans etkileri arttığından ortalama ısı geçiş kat sayısı da artmaktadır. Bu sayede tanka daha fazla miktarda enerji yüklenir. Manto giriş hızının $\dot{V}_{m}=2.5 \mathrm{l} / \mathrm{dk}$ ve $\dot{V}_{m}=5 \mathrm{l} / \mathrm{dk}$ olduğu durumda manto çıkış sıcaklığı kararlı hale ulaşmazken, $\dot{V}_{m}=$ $7.5 \mathrm{l} / \mathrm{dk}$ olduğu durumda test süresinin 130 dakikasından itibaren kararlı koşullara ulaşmıştır. Ayrıca Şekil 3 ve Şekil 4 beraber değerlendirildiği zaman, artan 1sı geçişi ile tank içerisindeki suyun sıcaklığının da arttığı gözlemlenmektedir.

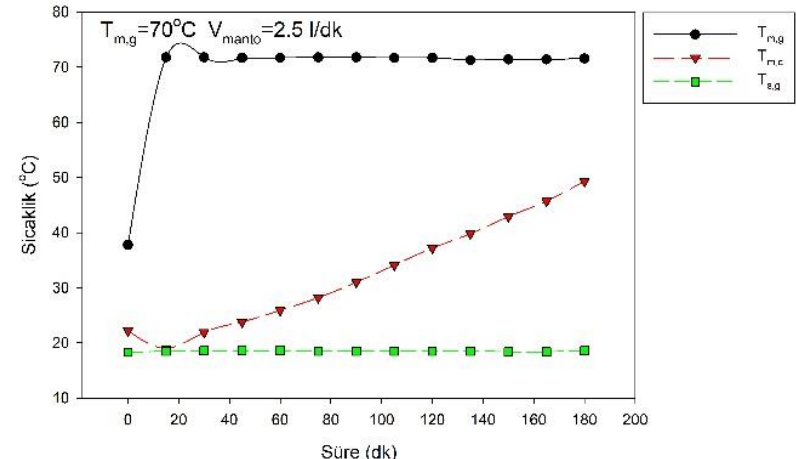

(a)

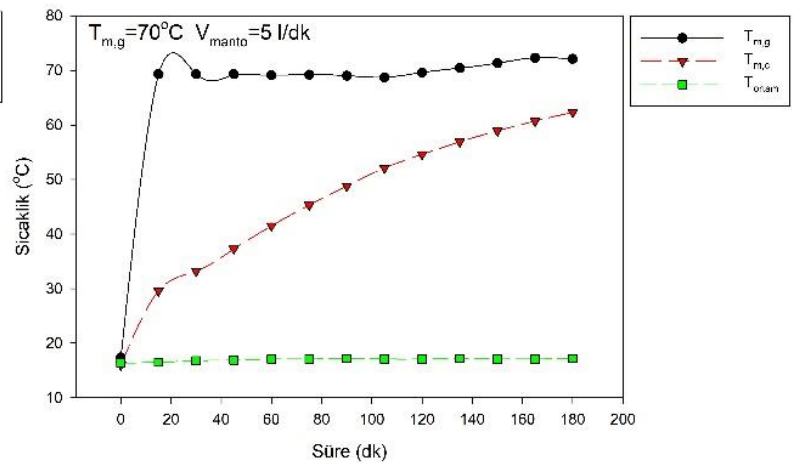

(b)

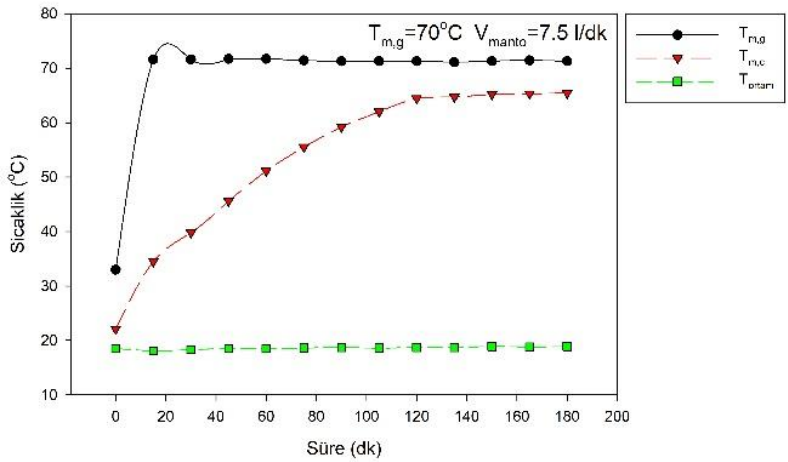

(c)

Şekil. 4. $T_{m, g}=70^{\circ} \mathrm{C}$ olduğu durumda farklı manto giriş hızları için manto giriş/çıkış ve ortam sıcaklıklarının zamanla değişimi (a) $\dot{V}_{m}=2.5 \mathrm{l} / \mathrm{dk}$; (b) $\dot{V}_{m}=5 \mathrm{l} / \mathrm{dk}$; (c) $\dot{V}_{m}=7.5 \mathrm{l} / \mathrm{dk}$ 
Şekil 5 'te incelenen bazı durumlar için 180 dakikalık enerji yükleme periyodu sonundaki tank içerisindeki sıcaklık görülmektedir. Şekil5'ten görüldüğü üzere, manto giriş sıcaklığı ile tank içerisindeki sıcaklık seviyesi önemli ölçüde değişim göstermiştir. Manto giriş sıcaklığındaki $10{ }^{\circ} \mathrm{C}$ artış, tank içerisindeki sıcaklığı yaklaşık olarak $5{ }^{\circ} \mathrm{C}$ artırmıştır. $\dot{V}_{m}=2.5 l / d k$ ve manto giriş sıcaklıklarının daha düşük olduğu $T_{m, g}=50^{\circ} \mathrm{C}$ ve $T_{m, g}=60^{\circ} \mathrm{C}$ olduğu durumda tank içerisindeki yaklaşık $100 \mathrm{~cm}$ 'ye kadar sıcaklık tabakalaşması bölgesi vardır. Artan manto giriş sıcaklığ 1 ile $T_{m, g}=70^{\circ} \mathrm{C}$ olduğu durumda tabakalaşma tank tabanından $40 \mathrm{~cm}$ 'ye kadar görülmüştür. Manto giriş debisinin $\dot{V}_{m}=5 l / d k$ ve $\dot{V}_{m}=7.5 l / d k$ olduğu durumlarda tüm manto giriş sıcaklıklarında yaklaşık olarak tank tabanından $50 \mathrm{~cm}$ 'ye kadar sıcaklık tabakalaşması vardır. Tank içerisindeki sıcaklık tabakalaşması durumları göz önünde bulundurulduğu zaman, daha fazla miktarda ve yüksek sıcaklıkta su depolamak için manto giriş debisinin ve sıcaklığının yüksek olması gerekmektedir.

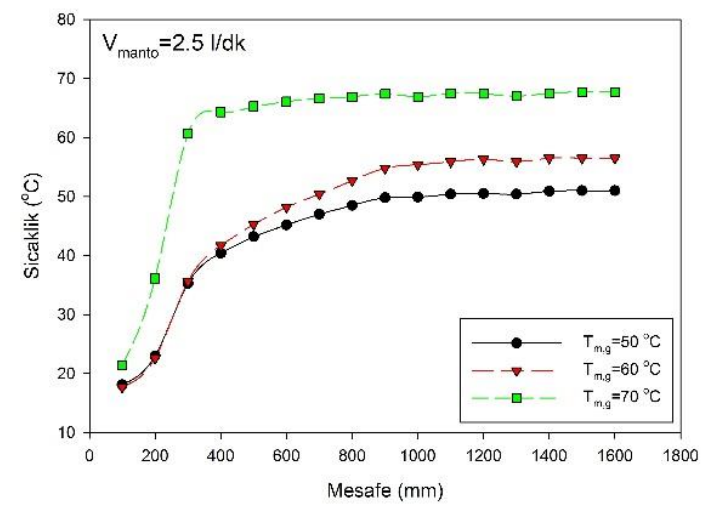

(a)

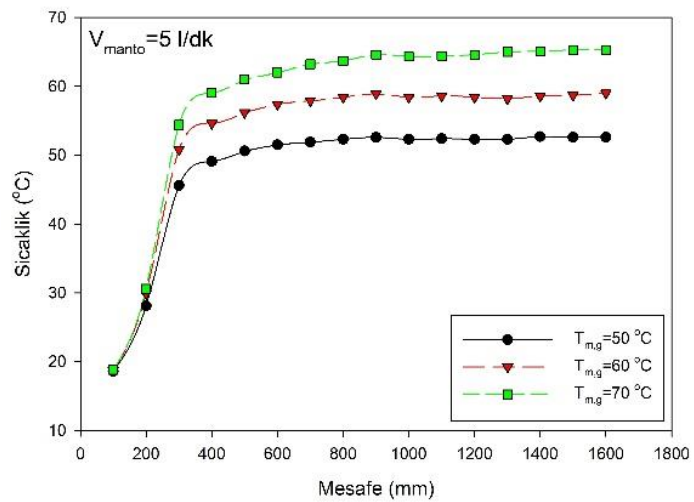

(b)

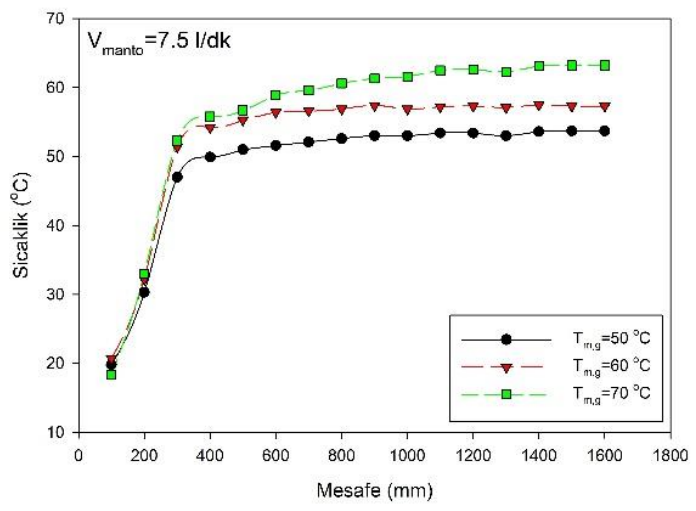

(c)

Şekil. 5. $180 \mathrm{dk}$ 'lık enerji yükleme periyodu sonunda manto giriş debilerine göre gruplandırılmış tank içerisindeki sıcaklık dağılımı (a) $\dot{V}_{m}=2.5 l / d k$; (b) $\dot{V}_{m}=5 l / d k$; (c) $\dot{V}_{m}=7.5 l / d k$

\subsection{Enerji Yükleme Periyodu için Sonuçlar}

Enerji boşaltma periyodu, bir sıcak su tankı için depolanan suyun direk olarak kullanılmasıdır. Kullanılacak suyun sıcaklık seviyesi ve miktarı bir sıcak su tankı için önemli performans ve memnuniyet kriterlerinden biridir. Genellikle bir sıcak su tankından mümkün olan en yüksek sıcaklıkta ve miktarda sıcak su elde edilmek istenir. Bu çalışmada enerji boşaltma periyodu, yükleme periyodunun hemen ardından başlatılmış ve kullanım suyu çıkış sıcaklığ $130{ }^{\circ} \mathrm{C}$ 'ye düşene kadar sürdürülmüştür. Bu çalışmada incelenen tüm durumlar için tanktan elde edilen sıcak su miktarları Şekil 6'da verilmiştir. Error! Reference source not found.' dan görüldüğü üzere, şebeke giriş debisi tanktan alınan sıcak miktarı üzerindeki önemli etkiye sahiptir. Aynı manto giriş sıcaklığı ve debisinde artan şebeke giriş debisi ile kullanılan sıcak su miktarı azalmıştır. Şebeke giriş debisi her 5 1/dk arttığında elde edilen sıcak su miktarı yaklaşık olarak 201 düşmüştür. Bu durum üzerinde en önemli etken tank girişinde yüksek akışkan hızına bağlı olarak karışma etkisinin artmasıdır. Şekil 6'dan manto giriş debisinin artmasıyla tanktan alınan sıcak su miktarının arttığı görülmektedir. Çünkü artan manto debisiyle sisteme daha enerji yüklendiği için sistemden daha fazla miktarda sıcak su elde edilebilmektedir, başka bir deyişle daha fazla miktarda enerji boşaltılabilmektedir. Artan manto giriş sıcaklığı ile tanktan elde edilen sıcak su miktarı da artmaktadır. Ancak bu artış manto debisinin ve şebeke giriş debisinin etkisine bakarak daha az seviyededir. Çünkü artan manto giriş sıcaklığı ile tank içerisindeki daha yüksek sıcaklıkta bu depolanmaktadır (Şekil 4). Bu durum ise bir miktar daha fazla sıcak su elde etmeye olanak sağlamaktadır. 


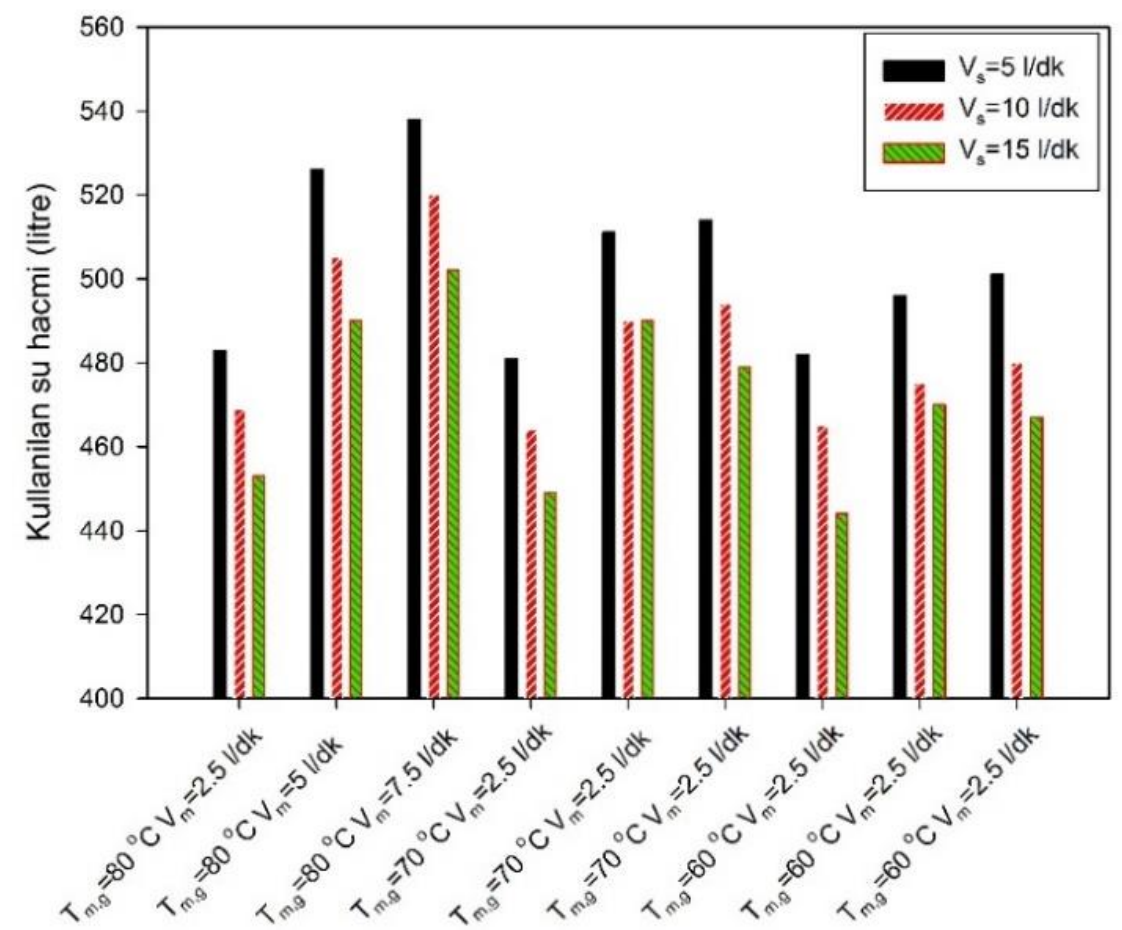

Şekil. 6. İncelenen tüm durumlar için enerji boşaltma periyodunda tanktan elde edilen sıcak su miktarları

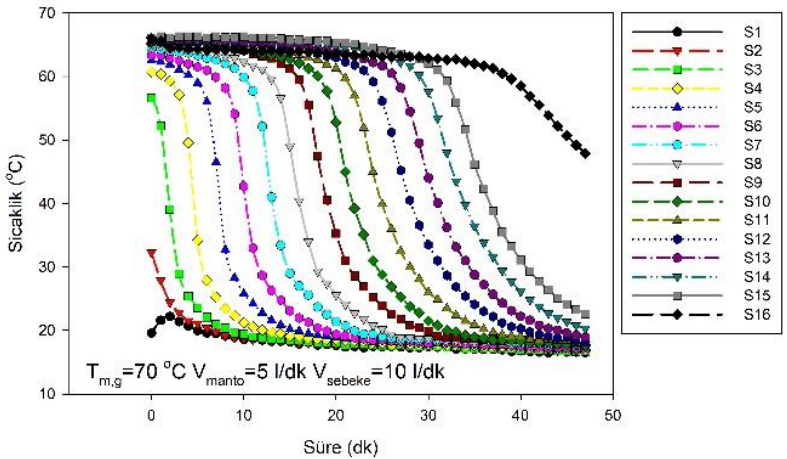

(a)

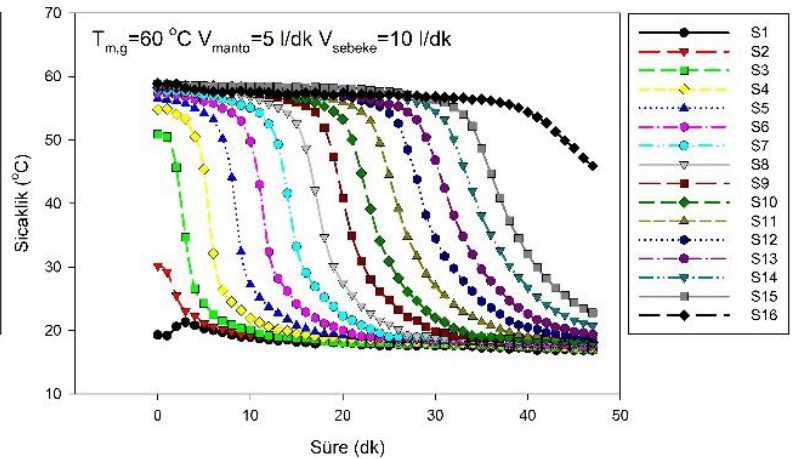

(b)

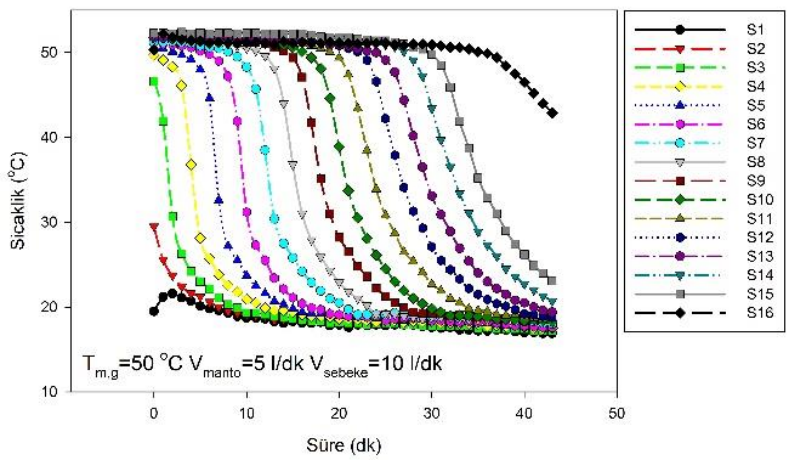

(c)

Şekil. 7. (a) $T_{m, g}=80^{\circ} \mathrm{C}$ ve $\dot{V}_{m}=5 \mathrm{l} / d k$; (b) $T_{m, g}=70{ }^{\circ} \mathrm{C}$ ve $\dot{V}_{m}=5 \mathrm{l} / d k$; (c) $T_{m, g}=60^{\circ} \mathrm{C}$ ve $\dot{V}_{m}=5 \mathrm{l} / d k$ olduğu durumlarda tank içerisindeki sıcaklık dağılımının zamanla değişimi

Şekil 7'de farklı manto giriş sıcaklıkları ile aynı manto giriș debisinde enerji yüklenmiş ve sabit enerji boşaltma debilerindeki sıcaklık dağılımlarının zamanla değişimi görülmektedir. Şekil 7'den görüldüğü üzere, tank içerisindeki sıcaklık tank tabanından başlayarak zaman içerisinde soğumaya başlamıştır. Tankın en üst kısmında kalan yüksek sıcaklık bölgesi nedeni sıcaklık sensörünün bulunduğu seviyenin kullanım suyu çıkış seviyesinin üst kısmında kalmasıdır. Bu bölgede kalan sıcak havadan hacmi bulunmaktadır. Tank içerisindeki sıcaklık dağılımının zamanla değişimi, farklı manto giriș debileri, manto giriș debileri ve şebeke giriş debileri için benzer davranışı göstermiştir. 


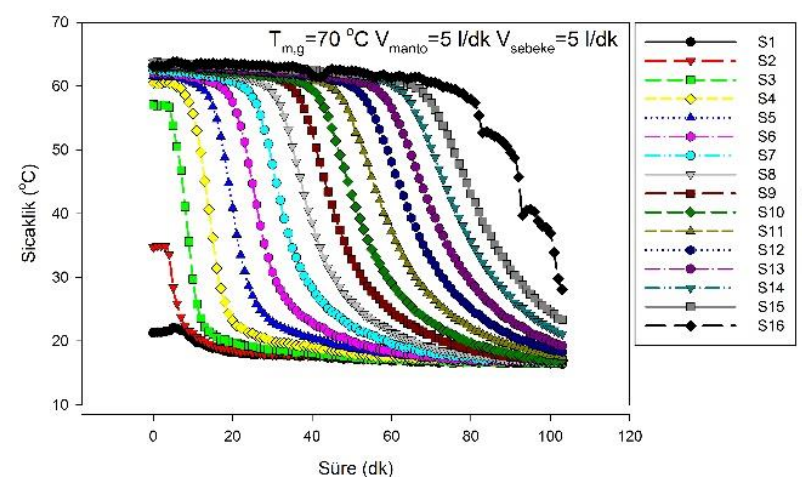

(a)

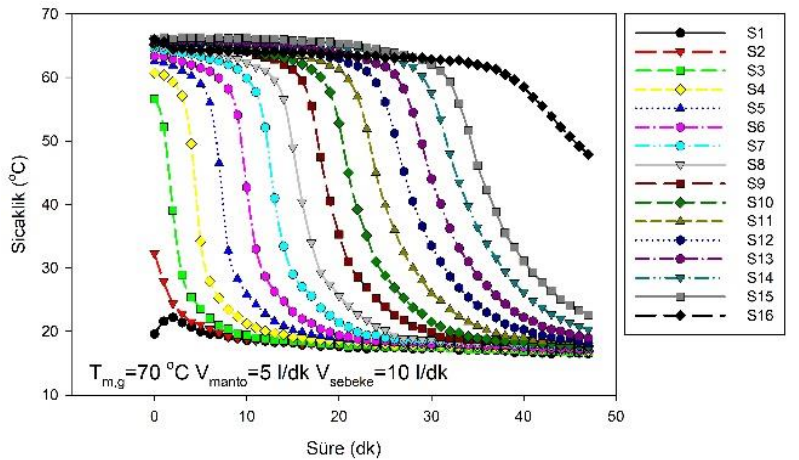

(b)

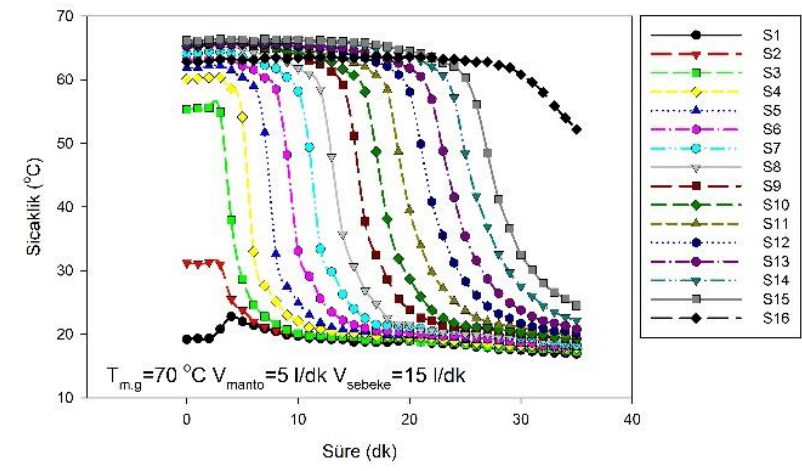

(c)

Şekil. 8. Farklı şebeke giriş debileri için tank içerisindeki sıcaklık dağılımının zamanla değişimi (a) $\dot{V}_{\text {sebeke }}=5 l / d k$; (b)

$$
\dot{V}_{\text {sebeke }}=10 \mathrm{l} / \mathrm{dk} ; \text { (c) } \dot{V}_{\text {sebeke }}=15 \mathrm{l} / \mathrm{dk}
$$

Şekil 8'de şebeke giriş debisinin tank içerisindeki sıcaklık dağılımı üzerindeki etkisi görülmektedir. Beklendiği üzere tank içerisindeki sıcaklık seviyesi yüksek şebeke giriş debilerinde daha hızlı düşmektedir. Şekil 8.a'da görüldüğü üzere, tankın üst kısmındaki hava hacmine bağlı olarak kalan sıcak bölge, şebeke giriş debisinin düşmesi ile daha düşük seviyelere gerilemiştir. Bu durum zaman içerisinde çevreye olan 1sı kaybının artmasından kaynaklanmaktadır. Şekil 7 ve Şekil 8'den görüldüğü üzere, tank içerisindeki sıcaklık dağılım karakteristiği tüm çalışma koşullarında benzerdir. Enerji boşaltma döneminde tank içerisindeki sıcaklık, tank tabanından üst kısımlarına doğru katman katman düşmüştür. Sicaklığı düşen bölgenin yerini şebeke suyu sıcaklığında soğuk su hacmi almıştır. Şebeke debisine göre sıcaklık düşümünün tank içerisindeki yayılması artan şebeke hızı ile artmıştır. Tank içerisindeki sıcaklık dağılımları tek başına enerji boşaltma periyodundaki performansı değerlendirmede yeterli olmayacağından, Şekil 7 ve Şekil 8'den elde edilen bulgular Şekil 6 ile değerlendirildiği zaman, şebeke giriş debisinin daha düşük olmasının sıcak su elde etme açısından daha iyi performans sağlayacağı görülmektedir.

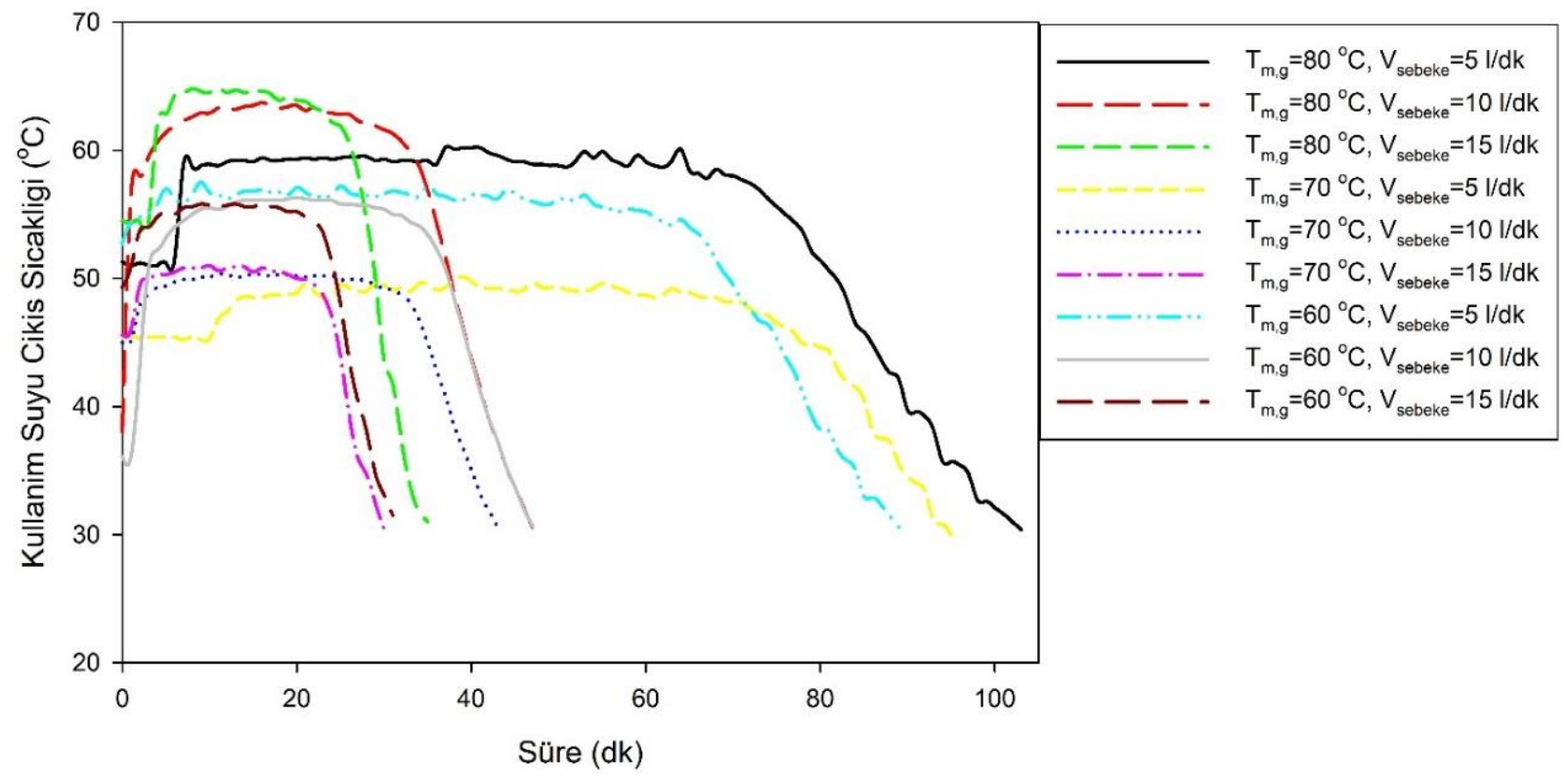

Şekil. 9. Kullanım suyu çıkış sıcaklığının zamanla değişimi (not: tüm durumlarda şebeke giriş debisi 5 l/dk'dır) 
Kullanım suyu sıcaklığının zamanla değişimi Şekil 9'da görülmektedir. Şekil 9'dan görüldüğü üzere, tank içerisindeki en yüksek sıcaklık seviyesindeki su belli bir süreye kadar tanktan elde edilmiştir. Daha sonra kullanım suyu çıkış sıcaklığ $\mathrm{h} ı \mathrm{zla} 30^{\circ} \mathrm{C}^{\prime} \mathrm{ye}$ düşmüştür. Suyun sıcaklığının düşme davranışı, tank içerisindeki sıcaklık seviyesi göre değişse de aynı sıcaklık seviyesi için benzerdir. Şekil 9'dan elde edilen bulgulardan görüldüğü üzere, tanktan elde edilen sıcak su miktarını arttırmak için ya en yüksek seviyeden alınan sıcak su miktarını arttırmak ya da sıcaklık düşümü sırasında geçen süreyi uzatmak gerekmektedir. Şekil 6 ve Şekil 9 birlikte değerlendirildiği zaman, bir düşey mantolu sıcak su tankından maksimum miktarda sicak su elde etmek için şebeke giriş debisinin düşük olması gerekmektedir.

\section{Sonuçlar}

$\mathrm{Bu}$ çalışmada sıcak su hazırlama sistemlerinde yaygın olarak kullanılan düşey mantolu sıcak su tanklarındaki sıcaklık tabakalaşmasını enerji yükleme ve boşaltma periyotları için deneysel olarak incelenmiştir. Çalışmada farklı manto giriş debisi, manto giriş sıcaklığı ve şebeke giriş debisinin etkileri araştırılmıştır. Çalışmanın sonucunda elde edilen sonuçlar aşağıda sıralanmıştır:

- Enerji yükleme periyodunda artan manto debisi ve manto giriş sıcaklığı tankta yüklenen enerji miktarını ve dolayısı ile tank içerisindeki sıcaklık seviyesini arttırmıştır.

- Enerji yükleme periyodunda farklı manto debisi ve manto giriş sıcaklığg ile tank içerisindeki sicaklık dağılım karakteristiği önemli ölçüde değişmemiştir. Sıcaklık dağılım karakteristiği tüm durumlarda benzer davranış göstermiştir.

- Enerji boşaltma periyodunda, sıcak su tankından elde edilen sıcak su hacminin üzerindeki en büyük etkiye şebeke debisi sahiptir. Artan şebeke giriş debisiyle sıcak su tankından elde edilen sıcak su miktarı azalmaktadır. Artan her 5 1/dk şebeke debisi yaklaşık olarak elde edilen sıcak su hacmini 20 litre düşürmüştür. Tanktan en yüksek miktarda sicak su elde etmek için şebeke giriş debisini düşük seviyede olması gerekmektedir.

- Artan manto giriş sıcaklığı ve manto debisi ile de tanktan elde edilen sıcak su miktarı artış eğilimi göstermektedir. Ancak manto giriş debisi ve sıcaklığının tanktan elde edilen sıcak su üzerindeki etkisi şebeke giriş debisine göre daha düşüktür.

- Sonuç olarak bir sıcak su tankından mümkün olan en yüksek sıcaklıkta ve miktarda sıcak su elde etmek için enerji yükleme periyodunda manto giriş debisi ve sıcaklığının yüksek olması ve şebeke giriş debisinin ise düşük olması gerekmektedir.

\section{Teşekkürler}

Bu çalışma TÜBİTAK 1002 Hızlı Destek Programı kapsamında 217M993 nolu proje kapsamında desteklenmiştir. Yazar sağlamış olduğu destekten dolayı TÜBİTAK'a teşekkürlerini sunar.

\section{Referanslar}

Acar, C. (2018). "A comprehensive evaluation of energy storage options for better sustainability." International Journal of Energy Research 0(0).

Arslan, M. and A. A. Igci (2015). "Thermal performance of a vertical solar hot water storage tank with a mantle heat exchanger depending on the discharging operation parameters." Solar Energy 116: 184-204.

Assari, M. R., H. Basirat Tabrizi and M. Savadkohy (2018). "Numerical and experimental study of inlet-outlet locations effect in horizontal storage tank of solar water heater." Sustainable Energy Technologies and Assessments 25: 181-190.

Bouhal, T., S. Fertahi, Y. Agrouaz, T. El Rhafiki, T. Kousksou and A. Jamil (2017). "Numerical modeling and optimization of thermal stratification in solar hot water storage tanks for domestic applications: CFD study." Solar Energy 157: $441-455$.

Chandra, Y. P. and T. Matuska (2019). "Stratification analysis of domestic hot water storage tanks: A comprehensive review." Energy and Buildings.

Dehghan, A. A. and A. Barzegar (2011). "Thermal performance behavior of a domestic hot water solar storage tank during consumption operation." Energy Conversion and Management 52(1): 468-476.

Deng, J., S. Furbo, W. Kong and J. Fan (2018). "Thermal performance assessment and improvement of a solar domestic hot water tank with PCM in the mantle." Energy and Buildings 172: 10-21.

Dincer, I. and M. A. Rosen (2011). Thermal Energy Storage Systems and Applications, Wiley and Sons, Ltd., Publication.

Dragsted, J., S. Furbo, M. Dannemand and F. Bava (2017). "Thermal stratification built up in hot water tank with different inlet stratifiers." Solar Energy 147: 414-425.

Erdemir, D. and N. Altuntop (2016). "Effect of thermal stratification on energy and exergy in vertical mantled heat exchanger." International Journal of Exergy 20(1): 105-121. 
Erdemir, D. and N. Altuntop (2016). "Improved thermal stratification with obstacles placed inside the vertical mantled hot water tanks." Applied Thermal Engineering 100: 20-29.

Fan, J. and S. Furbo (2012). "Thermal stratification in a hot water tank established by heat loss from the tank." Solar Energy 86(11): 3460-3469.

Fan, J., S. Furbo and H. Yue (2015). "Development of a Hot Water Tank Simulation Program with Improved Prediction of Thermal Stratification in the Tank." Energy Procedia 70: 193-202.

Fertahi, S. e.-D. n., A. Jamil and A. Benbassou (2018). "Review on Solar Thermal Stratified Storage Tanks (STSST): Insight on stratification studies and efficiency indicators." Solar Energy 176: 126-145.

Kenjo, L., C. Inard and D. Caccavelli (2007). "Experimental and numerical study of thermal stratification in a mantle tank of a solar domestic hot water system." Applied Thermal Engineering 27(11): 1986-1995.

Kurşun, B. (2018). "Thermal stratification enhancement in cylindrical and rectangular hot water tanks with truncated cone and pyramid shaped insulation geometry." Solar Energy 169: 512-525.

Kurşun, B. and K. Ökten (2016). "Sıcak Su Tanklarında Yalıtım Kalınlığının Isıl Katmanlaşmaya Etkisi." Gazi Üniversitesi Fen Bilimleri Dergisi Part C: Tasarım ve Teknoloji 6(1): 105-115.

Kurşun, B. and K. Ökten (2018). "Effect of rectangular hot water tank position and aspect ratio on thermal stratification enhancement." Renewable Energy 116: 639-646.

Zachár, A. (2015). "Investigation of a new helical flow distributor design to extract thermal energy from hot water storage tanks." International Journal of Heat and Mass Transfer 80: 844-857. 